\section{Bud Age Affects Sprouting and Flowering in Clementine Mandarin (Citrus reticulata Blanco)}

\author{
Andrew J. Krajewski ${ }^{1}$ and Etienne Rabe \\ Department of Horticultural Science, University of Stellenbosch, Private Bag \\ X1, Stellenbosch 7602, South Africa
}

Additional index words. hand pruning, regrowth, floral expression, growth flushes, leafaxillary buds, stems

\begin{abstract}
To investigate the effects of bud age on sprouting and flowering, bearing Clementine mandarin trees were hand-pruned at monthly intervals from late spring to fall. This pruning resulted in regrowth bearing axillary buds ranging in age from 9 to 5 months. After winter rest and during the return bloom, sprouting and flowering were assessed on axils on terminally positioned stems of these ages. The proportion of axillary buds sprouting and the number of spring shoots produced by each sprouting axillary site decreased with decreasing bud age. The proportion of axils sprouting one or more inflorescences, and the average number of flowers per stem also decreased with decreasing bud age. The number of axillary sites per stem, also significantly affected sprouting and flowering. Our results demonstrate the potential of hand-pruning to manipulate sprouting and return bloom depending on when in the summer or autumn the trees are pruned.
\end{abstract}

The perennial evergreen Citrus grows in flushes (Abbott, 1935; Cooper and Peynado, 1958; Furr and Armstrong, 1956; Schneider, 1973) that are synchronous under subtropical conditions (Davenport, 1990). In such areas, the main flushes arise in spring, summer, and fall (Monselise, 1985): July, December, and February under South African conditions. Axillary buds located on these flushes differ in their sprouting and flowering behavior in spring (Guardiola, 1981). An important factor influencing flowering is the location of inflorescences within the canopy, which is probably determined by internal factors connected with previous crop load and its effects on the extent of vegetative flushes before bud sprouting in spring (Goldschmidt and Monselise, 1972; Reuther, 1973; Sauer, 1951). Age and position of buds affect sprouting and flowering. These two factors are closely linked and affect the outcome of manipulations of flowering by pruning. The primary effect of pruning on flowering is reduction in bud count (Southwick and Davenport, 1987).

The proportion of buds sprouting in spring increased markedly with decreasing bud age (Guardiola, 1981; Guardiola et al., 1982). Guardiola (1981) reported that younger buds flowered more readily than older buds. Although some flowers arise on older branches

Received for publication 21 Nov. 1994. Accepted for publication 15 Aug. 1995. We gratefully acknowledge Slaley Farms and Schoongezicht Estates for providing trial sites and Shirley Brunette for providing technical assistance in conducting the trial. The cost of publishing this paper was defrayed in part by the payment of page charges. Under postal regulations, this paper therefore must be hereby marked advertisement solely to indicate this fact.

${ }^{1}$ To whom reprint requests should be addressed. Current address: Outspan International, P.O. Box 12154, Centrahil, Port Elizabeth 6006, South Africa.
(Lovatt et al., 1984), only buds $\leq 12$ months old at the time of sprouting contribute significantly to the formation of spring shoots after winter rest. Maximum flowering occurred on 1-year-old wood (Lovatt et al., 1984) and summer ( 8 months) or fall (5 months) flushes (Guardiola et al., 1977). Most reports document behavior of buds located on the three main flushes mentioned previously, and differences in sprouting and flowering are ascribed to the different ages of these flushes. However, there are two reasons why differences in flowering on these flushes may not be due just to age differences. First, the position within the canopy of these flushes, or bearing units, unspecified in the reports, also affects sprouting and flowering responses. Stems fall under progressively stronger apical control as they, themselves, relinquish terminal positions within the canopy and give rise to new flushes. Maximum flowering usually occurs on these recent flushes (Guardiola, 1981; Sauer, 1951), and removal of these terminally positioned units by heading allows axillary sites on subtending units to sprout (Krajewski and Rabe, 1995a). Buds on older twigs remained quiescent when a heavy flush occurred on younger twigs, although these older buds were otherwise able to sprout readily (Guardiola et al., 1977), which is presumably the case when they do not subtend more recent flushes. These older units also become shaded, which tends to inhibit budbreak (Lewis and McCarty, 1973). Because few reports disclose position within the canopy of different aged stems, one cannot ascertain whether heaviest flowering is associated with terminal positioning of stems or with bud age per sé. The effects of bud age and position on these aspects were recently reviewed (Krajewski and Rabe, 1995b).

Second, each flush arises and develops under distinct field conditions: the spring flush emerges after winter rest and floral inductive conditions; the summer flush arises under warm conditions and long photoperiods; and the fall flush comes under cooler conditions and shorter photoperiods. Therefore, flushes likely differ innately in more than simply their "age." If so, consequent effects on sprouting and flowering may exist, further affecting the outcome of pruning.

To investigate the effect of bud age on these responses, stems of various ages were created by pruning trees at monthly intervals from summer to autumn. To minimize variability due to bud position, sprouting and floral expression of leaf axillary buds were studied on terminally positioned stems arising as a consequence of the pruning. Counts were made during the return bloom after trees had gone through winter rest.

\section{Materials and Methods}

Plantmaterial. Five-and 6-year-old 'Nules' Clementine mandarin trees budded on Troyer citrange rootstocks were used, bearing their second and third commercial crops, respectively. The trees, situated near Stellenbosch, South Africa (long. $34^{\circ} \mathrm{S}$, lat. $19^{\circ} \mathrm{E}$, winter rainfall area, altitude $\approx 150 \mathrm{~m}$ ) were selected for uniformity of size, vigor, and crop load. The trees were pruned to similar severities at monthly intervals to force production of regrowth, and hence axillary buds, varying in age.

Pruning treatments. Twigs 8 to $15 \mathrm{~mm}$ in diameter were hand-pruned over the entire canopy of the trees, leaving stubs comprising up to eight axillary buds intact. This process was performed monthly commencing 4 weeks after $100 \%$ petal fall in summer until the following fall (5 months later) on the following dates: 31 Oct., 29 Nov., and 31 Dec. 1992 , and $30 \mathrm{Jan}$. and $28 \mathrm{Feb}$. 1993. The experiment was repeated at a different site the following year with trees pruned at similar times (1 Nov. and 1 Dec. 1993 and 1 Jan., 1 Feb., and 1 Mar. 1994) from summer to late fall. Axillary buds on these stubs started to sprout within 2 to 3 weeks of pruning, therefore producing regrowth stems bearing buds ranging in age from 9 to 5 months (from the time of sprouting in August), depending on when trees were pruned. The treatments were assessed on these new regrowth stems after winter rest during the return bloom.

Sprouting of leaf axillary buds on pruned stubs was monitored regularly. To standardize stem position, only terminal, unbranched stems arising as a result of pruning were tagged once the regrowth had ceased to expand. Ten tagged stems distributed around the canopy were assessed per tree, with 10 single-tree replicates per treatment arranged in a randomized block design. This procedure minimized any possible shading effects.

Assessments. Flowering was assessed in the spring following pruning (27 to 28 Sept. 1993; 28 to 30 Oct. 1994). The following variables were recorded for each tagged stem (100 per treatment): total number of leaf axils present, total number of axils sprouting inflorescences, and number of new leaves and 
flowers at each sprouted axil. The number of axils present per stem was recorded for use as a covariate.

Statistical analyses. Analyses of variance were performed using the general linear model procedure of the Statistical Analysis Services program (SAS, 1985). Analyses of proportions (percentage of axils sprouting; percentage of sprouting axils producing inflorescences) were performed on the following logarithmic (LOGIT) transformations according to Snedecor and Cochran's (1967) method: percent axils sprouting $=\log [$ (number of axils sprouting +0.5$) /($ total number of axils present - number of axils sprouting +0.5$)]$ and percent axils sprouting inflorescences $=\log [$ (number of axils sprouting inflorescences +0.5$) /($ number of axils sprouting - number of axils sprouting inflorescences +0.5$)$ ].

Means were separated by least significant difference.

\section{Results and Discussion}

General growth response. Regrowth was absent with pruning done later than the beginning of March. Because sprouting of twigs pruned after this time originated directly from axillary buds on the stubs, responses from these sites were not determined. After winter rest, trees started to sprout in August in both years. About one-half of the 9- and 8-monthold stems (pruned November and December, respectively) were positioned terminally by the time the trees entered winter rest, the remainder having given rise to one to two further flushes during the growing season. Most 7-month-old (pruned in January) and all 6- and 5-month-old stems were terminally positioned by this time. Only the terminally positioned stems arising from the treatment were used in this study.

Sprouting. Sprouting decreased with decreasing stem age, except for 5-month-old stems in 1993 (Table 1). Number of axils present affected sprouting only in $1994(P>\mathrm{F}$

Table 1. Sprouting of axillary buds on 'Clementine' mandarin stems of several ages.

\begin{tabular}{|c|c|c|}
\hline \multirow{2}{*}{$\begin{array}{l}\text { Age of stem } \\
\text { (months) }\end{array}$} & \multicolumn{2}{|c|}{$\begin{array}{c}\text { Proportion total no. } \\
\text { axillary sites sprouting }(\%)\end{array}$} \\
\hline & $1993^{y}$ & 1994 \\
\hline 9 & $50.9 \mathrm{a}$ & $70.9 \mathrm{a}$ \\
\hline 8 & $42.1 \mathrm{bc}$ & $67.6 \mathrm{a}$ \\
\hline 7 & $34.7 \mathrm{~cd}$ & $69.2 \mathrm{a}$ \\
\hline 6 & $32.4 \mathrm{~d}$ & $58.8 \mathrm{~b}$ \\
\hline 5 & $49.5 \mathrm{ab}$ & $45.7 \mathrm{c}$ \\
\hline \multicolumn{3}{|l|}{$P>\mathrm{F}$ levels $\mathrm{x}^{\mathrm{x}}$} \\
\hline Axil no./stem & NS & 0.0001 \\
\hline Linear & 0.0560 & 0.0731 \\
\hline Quadratic & 0.0001 & 0.0101 \\
\hline
\end{tabular}

${ }^{2}$ Values are expressed as a percentage of total number of leaf axillary sites sprouting toward full bloom on stems aged 9 to 5 months from the time of sprouting in spring (August). Analysis of percentages by LOGIT transformation; untransformed data shown.

${ }^{\mathrm{y} S e p a r a t i o n}$ of means in columns by least significant difference ( $t$ test) at $P \leq 0.05$.

xProbability levels given for number of axils per stem and time of pruning; NS = nonsignificant.
$=0.0001)$, although the effect of time of pruning (i.e., bud age) remained significant $(P>\mathrm{F}$ $=0.0001$ and 0.0101$)$. Our results conflict with those of other reports (Guardiola, 1981; Guardiola et al., 1982), which state that bud sprouting increased markedly with decreasing bud age.

The number of spring shoots produced per sprouting axillary site followed a similar trend, with fewer shoots sprouting with decreasing bud age (Table 2). Axil count $(P>\mathrm{F}=0.0022$ for 1994 and 0.0001 for 1995) and stem age ( $P$ $>\mathrm{F}=0.0117$ and 0.0179$)$ significantly affected this response. Again, our results conflict with other findings (Guardiola et al., 1982) in which the most shoots per sprouting axillary site were produced on 5-month-old buds and the fewest on 12- and 8-month-old buds. A possible explanation for this conflicting evidence may be that the 5-month-old buds referred to by Guardiola (1981) and Guardiola et al. (1982) sprouted more because they did not bear more recent flushes, whereas the older buds, those aged 12 (arising the previous spring) or 8 months (summer flush), were probably not positioned on stems situated terminally in the canopy. Therefore, these older buds may have been under apical control from more recent flushes, which decreases sprouting (Krajewski and Rabe, 1995a). The older buds also may have been shaded, depending on the position and orientation of their stems. Lewis and McCarty (1973) reported that shading decreased budbreak. Older shoots commonly produced more than one shoot per axil.

Flowering. The percentage of axils sprouting one or more inflorescences decreased with decreasing bud age $(P>\mathrm{F}=0.0001)$, even after adjustment for number of axils present $(P$ $>\mathrm{F}=0.0001$; Table 3). Again, these results conflict with those of Guardiola (1981), who stated that 5-month-old buds formed flowers more readily than 8- or 12-month-old buds. This result might have been a consequence of stem position because older stems usually subtend more recent units and themselves experience apical control.

A similar trend was found in the number of flowers formed per stem (Table 4). Flower count decreased with decreasing bud age more consistently in $1993(P>\mathrm{F}=0.0118)$ than in $1994(P>\mathrm{F}=0.0694)$. Axil count also affected this response $(P>\mathrm{F}=0.0001)$.

Although responses were studied in a relatively narrow range of buds aged 9 to 5 months and despite the significant effect of axil count on sprouting and flowering, bud age affected these responses. Our results do not support Guardiola et al.'s (1977) suggestion that sprouting and flowering are positively correlated. Sprouting percentages of $\approx 45 \%$ to $50 \%$ were recorded in the youngest buds formed ( 5 months old), yet after exposure during winter rest to the same inductive factors as older buds, only a low percentage of these youngest buds sprouted inflorescences and with very few flowers. Responses resulting from trees forced by pruning well may differ from situations where trees produce stems naturally. However, the trees used in our study were pruned to
Table 2. Number of spring shoots produced on 'Clementine' mandarin per sprouting axillary site.

\begin{tabular}{llc}
\hline \hline $\begin{array}{l}\text { Age of bearer } \\
\text { (months) }\end{array}$ & \multicolumn{2}{c}{ Shoots/sprouting axillary site } \\
\cline { 2 - 3 } & $1993^{\mathrm{y}}$ & 1994 \\
\hline 9 & $1.46 \mathrm{a}$ & $1.43 \mathrm{a}$ \\
8 & $1.38 \mathrm{a}$ & $1.20 \mathrm{~b}$ \\
7 & $1.12 \mathrm{~b}$ & $1.02 \mathrm{c}$ \\
6 & $1.11 \mathrm{~b}$ & $1.07 \mathrm{c}$ \\
5 & $1.02 \mathrm{~b}$ & $1.00 \mathrm{c}$ \\
$P>$ F levels & & \\
$\quad$ Axil no./stem & 0.0022 & 0.0001 \\
$\quad$ Times of pruning & & \\
$\quad$ Linear & 0.0003 & $\mathrm{NS}$ \\
$\quad$ Quadratic & 0.0117 & 0.0179 \\
\hline
\end{tabular}

${ }^{2}$ Values given are the mean number of spring shoots recorded toward full bloom per sprouting leaf axillary site on bearers aged 9 to 5 months.

${ }^{y}$ Separation of means in columns by least significant difference ( $t$ test) at $P \leq 0.05$.

xProbability levels given for number of axils per bearer and time of pruning; $\mathrm{NS}=$ nonsignificant.

Table 3. Proportions of leaf axillary sites sprouting inflorescences on 'Clementine' mandarin.

\begin{tabular}{lcc}
\hline \hline \multirow{2}{*}{$\begin{array}{l}\text { Age of bearer } \\
\text { (months) }\end{array}$} & \multicolumn{2}{c}{$\begin{array}{c}\text { Proportion sites sprouting } \\
\text { inflorescences }(\%)^{2}\end{array}$} \\
\cline { 2 - 3 } 9 & $1993^{\mathrm{y}}$ & 1994 \\
\hline 9 & $25.8 \mathrm{a}$ & $45.4 \mathrm{a}$ \\
8 & $96.5 \mathrm{a}$ & $97.9 \mathrm{a}$ \\
7 & $97.9 \mathrm{a}$ & $75.5 \mathrm{~b}$ \\
6 & $71.4 \mathrm{~b}$ & $41.1 \mathrm{c}$ \\
5 & $48.6 \mathrm{c}$ & $30.0 \mathrm{c}$ \\
$P>$ F levels & \\
Axil no./stem & $2.0 \mathrm{~d}$ & $9.3 \mathrm{~d}$ \\
Times of pruning & 0.0001 & 0.0001 \\
$\quad$ Linear & & \\
$\quad$ Quadratic & 0.0001 & 0.0001 \\
\hline
\end{tabular}

${ }^{2}$ Values are expressed as percentages of sprouting leaf axillary sites giving rise toward full bloom to one or more inflorescences on bearers aged 9 to 5 months.

${ }^{y}$ Analysis of percentages by LOGIT transformation; untransformed data shown. Separation of means in columns by least significant difference ( $t$ test) at $P \leq$ 0.05 .

xProbability levels given for number of axils per bearer and time of pruning; $\mathrm{NS}=$ nonsignificant.

Table 4. Number of flowers produced per bearer on 'Clementine' mandarin.

\begin{tabular}{lcc}
\hline \hline $\begin{array}{l}\text { Age of bearer } \\
\text { (months) }\end{array}$ & \multicolumn{2}{c}{ No. flowers $^{\mathrm{z}}$} \\
\cline { 2 - 3 } 9 & $1993^{\mathrm{y}}$ & 1994 \\
\hline 8 & $25.8 \mathrm{a}$ & $45.4 \mathrm{a}$ \\
7 & $18.3 \mathrm{~b}$ & $15.8 \mathrm{~b}$ \\
6 & $6.6 \mathrm{c}$ & $4.8 \mathrm{c}$ \\
5 & $2.6 \mathrm{~cd}$ & $3.4 \mathrm{c}$ \\
$P>$ F levels & $0.1 \mathrm{~d}$ & $0.5 \mathrm{c}$ \\
$\quad$ Axil no./stem & 0.0001 & 0.0001 \\
$\quad$ Times of pruning & & \\
$\quad$ Linear & 0.0001 & $\mathrm{NS}$ \\
$\quad$ Quadratic & 0.0118 & 0.0694 \\
\hline
\end{tabular}

${ }^{2}$ Values given are the mean number of flowers per bearer recorded toward full bloom on bearers aged 9 to 5 months.

'Separation of means in columns by least significant difference ( $t$ test) at $P \leq 0.05$.

xProbability levels given for number of axils per bearer and time of pruning; NS = nonsignificant. 
a similar extent, and there were significant effects based on the time at which trees were pruned. Therefore, the results suggest that the responses recorded by other authors on naturally occurring flushes can not only be ascribed to the age of the buds located on these stems but also to their position.

Although we cannot exclude the possibility that flushes differ innately due to their development under different temperatures and photoperiods, within the limitations of field studies, our results show that bud age influences sprouting and production of vegetative and reproductive shoots by 'Clementine' mandarin stems. Selective pruning, therefore, is a practical means by which return bloom can be manipulated. This finding has three important applications in control of flowering by producers: 1) young trees may be pruned at different times to manipulate budbreak and hence tree complexity, which may bring trees into production earlier. 2) Trees bearing a heavy crop are unlikely to flush while the crop is developing on the trees (Goldschmidt and Monselise, 1972; Reece, 1945; Sauer, 1951). The consequent lack of bearing sites for the return bloom (Monselise and Goldschmidt, 1982; Mullins et al., 1989) may result in alternate bearing; however, pruning can be used to force trees to flush in heavy bearing situations where they would not normally do so. The creation of these bearing sites could modulate or prevent the alternate bearing tendency. 3) Our results demonstrate the effect of time of pruning on return bloom through changes in proportions of axils sprouting inflorescences and flower counts. Thus, pruning places control of return bloom within the citrus producer's grasp.

\section{Literature Cited}

Abbott, C.E. 1935. Blossom-bud differentiation in citrus trees. Amer. J. Bot. 22:476-485.

Cooper, W.C. and A. Peynado. 1958. Effect of gibberellic acid on growth and dormancy in citrus. Proc. Amer. Soc. Hort. Sci. 72:284289.

Davenport, T.L. 1990. Citrus flowering. Hort. Rev. 12:349-408.

Furr, J.R. and W.W. Armstrong. 1956. Flower induction in Marsh grapefruit in the Coachella Valley, California. Proc. Amer. Soc. Hort. Sci. 67:176-182.

Goldschmidt, E.E. and S.P. Monselise. 1972. Physiological assumptions towards the development of a citrus fruiting model. Proc. Intl. Soc. Citricult. 2:668-672.

Guardiola, J.L. 1981. Flower initiation and development in citrus. Proc. Intl. Soc. Citricult. $2: 242-246$

Guardiola, J.L., M. Agusti, and F. Garcia-Mari. 1977. Gibberellic acid and flower bud development in sweet orange. Proc. Intl. Soc. Citricult. 2:696-699.

Guardiola, J.L., C. Monerri, and M. Agusti. 1982. The inhibitory effect of gibberellic acid on flowering in Citrus. Physiol. Plant. 55:136142.

Krajewski, A.J. and E. Rabe. 1995a. Effect of heading and its timing on flowering and vegetative shoot development in Clementine mandarin (Citrus reticulata Blanco). J. Hort. Sci. 70:445-451.

Krajewski, A.J. and E. Rabe. 1995b. Citrus flowering: A critical evaluation. J. Hort. Sci. 70:357374.

Lewis, L.N. and C.D. McCarty. 1973. Pruning and girdling of citrus, p. 211-229. In: W. Reuther (ed.). The citrus industry. vol. 3. Univ. of California, Berkeley.

Lovatt, C.J., S.M. Streeter, T.C. Minter, N.V.
O'Connell, D.L. Flaherty, M.W. Freeman, and P.B. Goodell. 1984. Phenology of flowering of Citrus sinensis (L.) Osbeck, cv. Washington navel orange. Proc. Intl. Soc. Citricult. 1:186190.

Monselise, S.P. 1985. Citrus and related genera, p. 275-294. In: A.H. Halevy (ed.). CRC handbook of flowering, vol. II. CRC Press, Boca Raton, Fla.

Monselise, S.P. and E.E. Goldschmidt. 1982. Alternate bearing in fruit trees. Hort. Rev. 4:128173.

Mullins, M.G., J.A. Plummer, and A.M. Snowball. 1989. Flower initiation: New approaches to the study of flowering perennial plants, p. 65-77. In: C.J. Wright (ed.). Manipulation of fruiting. Butterworths, London.

Reece, P.C. 1945. Fruit set in the sweet orange in relation to flowering habit. J. Amer. Soc. Hort. Sci. 4:81-86.

Reuther, W. 1973. Climate and citrus behaviour, p. 280-337. In: W. Reuther (ed.). The citrus industry. vol. 3. Univ. of California, Berkeley.

SAS Institute. 1985. SAS user's guide: Basics. version 5 ed. SAS Inst., Cary, N.C.

Sauer, M.R. 1951. Growth of orange shoots. Austral. J. Agr. Res. 2:105-117.

Schneider, H. 1973. The anatomy of citrus, p. 185. In: W. Reuther, L.D. Batchelor, and H.J. Webber (eds.). The citrus industry. vol. 2. Univ. of California, Berkeley.

Snedecor, G.W. and W.G. Cochran. 1967. Twoway classifications with unequal numbers and proportions, p. 497-498. In: G.W. Snedecor and W.G. Cochran (eds.). Statistical methods. 6th ed. Iowa State Univ. Press, Ames.

Southwick, S.M. and T.L. Davenport. 1987. Modification of the water stress-induced floral response in 'Tahiti' lime. J. Amer. Soc. Hort. Sci. 112:231-236. 